\title{
Removal of Azo Dye Methyl Orange in Aqueous Solution by Kaolinite Clay: Equilibrium Isotherms, Kinetics and Error Analyses
}

\author{
Umar Omeiza Aroke ${ }^{1 *}$, Raheem Omuya Momoh ${ }^{2}$, Lucas Albert Jerome Hamidu ${ }^{3}$ and Umar Buhari ${ }^{1}$
}

${ }^{1}$ Department of Chemical Engineering, Abubakar Tafawa Balewa University, Bauchi

${ }^{2}$ Department of Chemical Engineering, Ahmadu Bello University, Zaria-Kaduna

${ }^{3}$ Nigeria Building and Road Research Institute, 10 NBRRI Way/I.T. Igbani Street, off Awolowo Way, Jabi, Abuja, Nigeria

DOI: $10.36348 /$ sjet.2020.v05i11.005

| Received: 09.10.2020 | Accepted: 22.10.2020 | Published: 16.11 .2020

*Corresponding author: Umar Omeiza Aroke

Abstract

Decolourisation of wastewater, particularly from textile industries is one of the major environmental concerns these days. The limitations of most of these treatment methods are their high operational and maintenance costs cannot effectively be used to treat wide range of such wastewater. This work describes the use of kaolinite clay as an efficient adsorbent material for anionic azo dye methyl orange removal from synthesized wastewater. Batch adsorption experiment of 200 $\mathrm{mgL}^{-1}$ azo dye methyl orange contaminant removal using kaolinite clay at different stirring speed: 100, 200, 300, 400 and $500 \mathrm{rpm}$ at constant $\mathrm{pH} 4$ and contact time of $(0-180)$ minutes were investigated, thus, adsorption increases with increase in stirring speed with maximum removal of $69.90 \%$ and maximum adsorptive capacity of $3.476 \mathrm{mg} / \mathrm{g}$ at 500 rpm. The adsorption equilibrium data were well described by Langmuir $>$ Freundlich $>$ Koble-Corrigan whilst adsorption kinetic data by pseudo second-order>pseudo first-order>intraparticle diffusion $>$ Reichenberg equation in the stated order based on high correlation coefficients and relatively small values of error function analyses ( $\chi^{2}$, RMSE, NSD and ARE). The adsorption processes were controlled by chemisorption. The potential applicability of Alkaleri kaolinite clay from Northeast-Nigeria could be employed as a low-cost adsorbent alternative to commercial/activated carbon in the removal of azo dye methyl orange from wastewater.

Keywords: Adsorption, Methyl orange, Kaolinite clay, Isotherms, Kinetics, Error function.

Copyright (C) 2020 The Author(s): This is an open-access article distributed under the terms of the Creative Commons Attribution 4.0 International License (CC BY-NC 4.0) which permits unrestricted use, distribution, and reproduction in any medium for non-commercial use provided the original author and source are credited.

\section{INTRODUCTION}

The rapid growth in global population and advancements in industry, commerce and agriculture demand the use of large amount of energy, as a result create large quantities of wastes and increase in complexity of toxic effluents discharged into the environment that should be disposed-off with minimum negative environmental effects and costs [2]. Most industries especially textiles, paper, plastics, leather, food, cosmetics etc use dyes to colour their final products. Such extensive use of dyes poses problems in form of coloured wastewater which require pretreatment for colour prior to disposal into receiving water bodies. This is because this dye-bearing wastewater imparts toxicity to aquatic life and damage the aesthetic nature of receiving water body's' environment [40, 45]. Many dyes are visible in water at very low concentrations. The dye concentrations in the textile processing wastewaters are in the range of (10200) $\mathrm{mgL}^{-1}$ [41]. Therefore, usually the discharge of highly coloured wastewater in open waters presents aesthetic problem. As dyes are designed to be chemically and photolytically stable, they are highly persistent in natural environments. The compounds which absorb electromagnetic energy in the visible range $(\sim 350-700) \mathrm{nm}$ are coloured. These coloured compounds are known as dyes. Dyes contain chromophores (delocalised electron systems with conjugated double bonds) and auxochromes (electron withdrawing or electron donating substituents) [47]. The chromophore imparts the colour to the dye molecule and auxochrome intensifies the colour of the chromophore by altering the overall energy of the electron system. Usual chromophores are $\mathrm{C}=\mathrm{C}, \mathrm{C}=\mathrm{N}$, $\mathrm{C}=\mathrm{O}, \quad \mathrm{N}=\mathrm{N}, \quad \mathrm{NO}_{2}$ and quinoid rings while the auxochromes are $-\mathrm{NH}_{3},-\mathrm{COOH}, \mathrm{SO}_{3} \mathrm{H}$ and $-\mathrm{OH}$ [47].

The main source of discharge of dyes is textile industries where they are used to colour products. There are over 1,000,000 dyes for commercial use and around 700 tons of dyestuffs are produced annually [18]. The types of dyes are mainly basic dyes, acid dyes, direct dyes, reactive dyes, mordant dyes, azo dyes, disperse 
dyes and sulphur dyes. Azo dyes are the largest class of dyes with the greatest variety of colours approximately $(10-15)$ percent of the dyes are released into the environment during dyeing of different substrates [13]. Azo dyes containing sulfonate groups as substituent are called as sulphonated azo dyes. Azo groups in conjugation with aromatic substituents or enolizable groups make a complex structure which lead to huge expression of variation of colours in dyes [33, 49].

Methyl orange (CAS No. 547-58-0) a dark red crystalline odourless powder is categorised as anionic azo dye due to the presence of anionic functional group of $=\mathrm{NaO}_{3} \mathrm{~S}^{-}$with molecular formula: $\mathrm{C}_{14} \mathrm{H}_{14} \mathrm{~N}_{3} \mathrm{NaO}_{3} \mathrm{~S}$, molar mass: $327.33 \mathrm{~g} \cdot \mathrm{mol}^{-1}$, density: $1.28 \mathrm{~g} / \mathrm{cm}^{3}$, solid, melting point $>300{ }^{\circ} \mathrm{C}(573 \mathrm{~K})$, solubility in water: 0.5 $\mathrm{g} / 100 \mathrm{~mL}\left(20^{\circ} \mathrm{C}\right)$. Methyl orange powder (Fig. 1) is a carcinogenic water soluble azo dye which is widely used in textile industries, manufacturing printing paper, and research laboratories. It is also metabolised into aromatic amines by intestinal microorganisms. Methyl orange is stable, shows low biodegradability and is soluble in water hence it is difficult to remove from aqueous solutions by common water purification treatment method [17].<smiles>CN(C)c1ccc(/N=N/c2ccc(S(=O)(=O)O[AlH2])cc2)cc1</smiles>

Fig-1: Azo dye methyl orange structure

Dyeing effluents have a serious environmental impact because disposal of these effluents into the receiving water body causes damage to aquatic biota or humans by mutagenic and carcinogenic effects [12]. Therefore, the effluents being generated by industries rich in basic azo dyes required treatment before being discharged into the water bodies. Treatment of effluent containing synthetic dye stuffs is very difficult, since the dyes are stable in conditions of light and heat, in the presence of oxidizing agents and are resistant to aerobic digestion [26]. Several physical, chemical and biological treatment methods (e.g., adsorption, coagulation-flocculation, biodegradation, ion-exchange, chemical oxidation, ozonation, reverse osmosis, membrane filtration and electrochemical methods) have been applied to remove dye molecules from such effluent [12]. However, these processes vary in their effectiveness, cost and environmental impact. Among these, adsorption has been proven to be an excellent method to remove dye from contaminated water. Adsorption is a more competitive treatment process for dye removal because of its simplicity, high efficiency, and wide-ranging availability and advantages over the others mentioned [5].

Clays play an important role in the environment by acting as a scavenger of pollutants by taking up cations and anions either through ion exchange or adsorption or both $[8,20]$. Kaolin clay has a melting point of $1760{ }^{\circ} \mathrm{C}$; the colour of all varieties is white but inferior grades burn to a yellow or brownish colour [7]. The exchangeable cations are $\mathrm{Na}^{+}, \mathrm{K}^{+}, \mathrm{Ca}^{2+}$ and $\mathrm{Al}^{+3}$ [31]. Kaolinite, the main constituent of kaolin clay, is formed by rock weathering. It is white, greyishwhite, or slightly coloured. It is made up of tiny, thin, pseudo hexagonal, flexible sheets of triclinic crystal with a diameter of $(0.2-12) \mu \mathrm{m}$. It has a density of $(2.1$ - 2.6) $\mathrm{g} / \mathrm{cm}^{3}$. The cationic exchange capacity of kaolinite is considerably less in the order of $(2-10)$ meq/100 g, depending on the particle size, but the rate of the exchange reaction is rapid, almost instantaneous [9].

There is a growing requirement for more efficient and cost-effective batch/column adsorption for the decolourization of dyes-bearing wastewater. Clays are abundantly available, low cost, and interestingly possess unique adsorption capacities for water pollutants, thus; a promising alternative to the commercial adsorbents/activated carbons in the adsorption of heavy metals/dyes [27]. Therefore, the aim of this work is to explore the suitability of natural Alkaleri kaolinite clay as an efficient adsorbent material for anionic azo dye methyl orange removal from wastewater. Some of its specific objectives include: different adsorption isotherm models, adsorption kinetics models and effects of some operation parameters on the performance of the adsorbent.

\section{EXPERIMENTAL SECTION \\ Materials and Chemicals}

Pre-treated and physical beneficiated kaolin clay from Alkaleri LGA of Bauchi State, NortheastNigeria of known properties and characteristics reported in a separate publication [8] was used without further treatment/purification. The anionic azo dye methyl orange powder, hydrochloric acid and sodium hydroxide of analytical grade manufactured by Solvay Chemicals International Limited, Brussels used were purchased in local chemicals shop in Bauchi Metropolis, Northeast-Nigeria.

\section{Preparation of anionic azo dye methyl orange contaminant \\ The stock solution of contaminant was} prepared by dissolving $0.5 \mathrm{~g}$ of analytical grade azo dye methyl orange in $1000 \mathrm{~mL}$ of distilled water to make a stock solution of $500 \mathrm{mgL}^{-1}$ and serial dilution method applied to working solution of $200 \mathrm{mgL}^{-1}$. All experiments were carried out at room temperature $(25 \pm$ $\left.1{ }^{\circ} \mathrm{C}\right)$ under varying stirring speed of $(100-500) \mathrm{rpm}$. The concentration of stock solution was verified using 
digital Ultra Violet (UV) spectrophotometer (model: UNICAM 969 A.A-650) and $\mathrm{pH}$ verified using digital pH meter (model: Jenway, $3510 \mathrm{pH}$ meter).

\section{Batch adsorption experiments}

Batch mode experiment were carried out in orbital shaker (model: Stuart Scientific SOI.101) using $500 \mathrm{ml}$ conical flasks containing $10 \mathrm{~g}$ of adsorbent with $200 \mathrm{ml}$ of contaminant solution after which the $\mathrm{pH}$ was adjusted to 4.0 using $0.1 \mathrm{M}$ hydrochloric acid. The mixture was placed on an orbital shaker and shaken periodically at stirring speed of $100 \mathrm{rpm}$ and $20 \mathrm{ml}$ sample mixture collected at different contact time of 30 , $60,90,120,150$ and 180 minutes. These were repeated for 200, 300, 400 and $500 \mathrm{rpm}$ stirring speed to study the effect on azo dye sorption onto kaolinite clay. The sample mixtures collected were filtered through

$$
\mathrm{q}_{\mathrm{e}}=\left(\mathrm{C}_{\mathrm{o}}-\mathrm{C}_{\mathrm{e}}\right) \frac{\mathrm{v}}{\mathrm{m}}
$$

Filtration membranes (Tianjin Do-Chrom Technology Co., Ltd.) pore size $0.45 \mu \mathrm{m}$. The residual equilibrium concentrations of azo dye methyl orange solution in the filtrate were determined by UV Spectrophotometer. The maximum wavelength $\left(\lambda_{\max }\right)$ for the azo dye methyl orange was measured at $470 \mathrm{~nm}$, concentrations were determined from a standard calibration curve using Microsoft excel spread sheet. Differences between the initial and final (residual) concentrations were recorded as the amount of azo dye methyl orange removed from contaminant solution.

In order to obtain the sorption characteristics of the adsorbent with respect to azo dye methyl orange, the adsorption capacities expression was used in analyzing the data obtained from the adsorption experiments Eq. (1) [10].

The adsorption behaviours of the samples were studied by evaluating the percentage removal efficiency of azo dye methyl orange calculated from Eq. (2) [4].

$$
\text { Removal efficiency }=\left[\frac{C_{o}-C_{e}}{C_{o}}\right] \times 100
$$

Where $\mathrm{q}_{\mathrm{e}}$ is the equilibrium adsorptive capacity of adsorbent $(\mathrm{mg} / \mathrm{g}), \mathrm{C}_{\mathrm{o}}$ and $\mathrm{C}_{\mathrm{e}}$ are initial and equilibrium dye concentrations, respectively $\left(\mathrm{mgL}^{-1}\right), v$ is dye solution volume $(\mathrm{L})$ and $\mathrm{m}$ is the mass of adsorbent $(\mathrm{g})$.

The equilibrium adsorption isotherm is fundamentally important in the design of adsorption systems. The relationships between sorbent and sorbate are described by adsorption isotherms, usually the ratio between the quantity sorbed and that remaining in the solution at a fixed temperature at equilibrium [21]. In other words, a plot obtained between the amount of substance adsorbed per unit mass of the adsorbent and the pressure (in case of a gas) or concentration (in case of solution) at constant temperature is known as the adsorption isotherm [43]. Kinetic models have been used to investigate the mechanism of sorption and potential rate controlling steps, which is helpful for selecting optimum operating conditions for the full$\mathrm{R}_{\mathrm{L}}=\frac{1}{1+\mathrm{bC}_{\mathrm{o}}}$

$R_{L}$ values between 0 and 1 indicate favourable adsorption, while $\mathrm{R}_{\mathrm{L}}>1, \mathrm{R}_{\mathrm{L}}=1$, and $\mathrm{R}_{\mathrm{L}}=0$ indicate scale batch process [1]. In this work, three adsorption isotherms and four kinetic models were tested by applying their linearized form for the best fit of experimental data. Also, error analysis for the adsorption system was carried out to confirm the model fit.

\section{Langmuir isotherm}

The nonlinear and linear form of Langmuir isotherm model is written as in Table 1 (Eq. (4)) [16], where $\mathrm{b}$ is the equilibrium constant $(\mathrm{L} / \mathrm{mg})$ larger $\mathrm{b}$ value represents higher adsorption energy and $\mathrm{q}_{0}$ is the maximum sorption capacity corresponding to complete monolayer coverage $(\mathrm{mg} / \mathrm{g})$.

The dimensionless constant of the separation factor or equilibrium parameter $R_{L}$ to predict the adsorption efficiency and usability of the Langmuir equation is determined as Eq. (3) [37]:

unfavourable, linear and irreversible adsorption process respectively [37]. 
Umar Omeiza Aroke et al; Saudi J Eng Technol, Nov, 2020; 5(11): 422-433

\begin{tabular}{|l|c|c|c|c|}
\hline \multicolumn{2}{|c}{ Table-1: List of adsorption isotherm models } & Plot \\
\hline Isotherm & $\begin{array}{l}\text { Nonlinear } \\
\text { form }\end{array}$ & Linear form & $\frac{\mathrm{C}_{\mathrm{e}}}{\mathrm{q}_{\mathrm{e}}}$ vs. $\mathrm{C}_{\mathrm{e}}$ & $(4)$ \\
\hline Langmuir & $\mathrm{q}_{\mathrm{e}}=\frac{\mathrm{q}_{\mathrm{o}} \mathrm{bC}}{1+\mathrm{b} \mathrm{C}_{\mathrm{e}}}$ & $\frac{\mathrm{C}_{\mathrm{e}}}{\mathrm{q}_{\mathrm{e}}}=\frac{1}{\mathrm{q}_{0} \mathrm{~b}}+\frac{\mathrm{C}_{\mathrm{e}}}{\mathrm{q}_{0}}$ & $\log \mathrm{q}_{\mathrm{e}}$ vs. $\log \mathrm{C}_{\mathrm{e}}$ & $(5)$ \\
\hline Freundlich & $\mathrm{q}_{\mathrm{e}}=\mathrm{K}_{\mathrm{F}} \mathrm{C}_{\mathrm{e}}^{\frac{1}{\mathrm{n}}}$ & $\log \mathrm{q}_{\mathrm{e}}=\log \mathrm{K}_{\mathrm{F}}+\frac{1}{\mathrm{n}} \log \mathrm{C}_{\mathrm{e}}$ & - & $(6)$ \\
\hline Koble-Corrigan & $\mathrm{q}_{\mathrm{e}}=\frac{\mathrm{AC}_{\mathrm{e}}^{\mathrm{n}}}{1+\mathrm{BC}_{\mathrm{e}}^{\mathrm{n}}}$ & $\frac{1}{\mathrm{q}_{\mathrm{e}}}=\frac{1}{\mathrm{AC}}+\frac{\mathrm{B}}{\mathrm{A}}$ & & \\
\hline
\end{tabular}

Freundlich isotherm: This empirical model can be applied to multilayer adsorption, with non-uniform distribution of adsorption heat and affinities over the heterogeneous surface [23, 42]. The nonlinear and linear form of Freundlich isotherm model can be expressed as in Table 1 (Eq. (5)) $[6,16]$, where $\mathrm{K}_{\mathrm{F}}$ is the adsorption coefficient (relative adsorption capacity of adsorbent) and $1 / \mathrm{n}$ indicates the adsorption intensity of adsorbate onto adsorbent. The slope $(1 / \mathrm{n})$ between 0 and 1 indicates favorable adsorption isotherm [37].

Koble-Corrigan isotherm: The nonlinear and linear form is computed as in Table 1 (Eq. (6)) [16], where $\mathrm{A}\left(\mathrm{L}^{\mathrm{n}} \mathrm{mg}^{1-\mathrm{n}} \mathrm{g}^{-1}\right), \mathrm{B}(\mathrm{L} / \mathrm{mg})^{\mathrm{n}}$ are Koble-Corrigan constants and $\mathrm{n}$ is the Koble-Corrigan model exponent. This model is valid only when $n>1$ [1]. The three isotherm parameters $\mathrm{A}, \mathrm{B}$ and $\mathrm{n}$ are evaluated from the linear plot using a trial and error optimisation using Microsoft excel spread sheet solver [24].

Pseudo first-order kinetic: The nonlinear and the integrated linear form of pseudo first-order kinetic is written as in Table 2 (Eq. (7)) [28], where $q_{t}$ is the adsorptive capacity of adsorbent at time $\mathrm{t}(\mathrm{mg} / \mathrm{g}), \mathrm{K}_{1}$ is the pseudo first-order rate constant $\left(\mathrm{min}^{-1}\right)$ and $\mathrm{t}$ is the time (min). The value of rate constant $\mathrm{K}_{1}=-2.303 \times$ slope of the plot $[28,34]$.

Table-2: Lists of adsorption kinetic models

\begin{tabular}{|l|c|c|c|c|}
\hline Kinetic & Nonlinear & Linear & Plot & Equation \\
\hline Pseudo first-order & $\mathrm{q}_{\mathrm{t}}=\mathrm{q}_{\mathrm{e}}\left(1-\exp ^{\mathrm{K}_{\mathrm{t}} \mathrm{t}}\right)$ & $\log \left(\mathrm{q}_{\mathrm{e}}-\mathrm{q}_{\mathrm{t}}\right)=\log \mathrm{q}_{\mathrm{e}}-\frac{\mathrm{K}_{1}}{2.303} \mathrm{t}$ & $\log \left(\mathrm{q}_{\mathrm{e}}-\mathrm{q}_{\mathrm{t}}\right)$ vs. $\mathrm{t}$ & $(7)$ \\
\hline Pseudo second-order & $\mathrm{q}_{\mathrm{t}}=\frac{\mathrm{K}_{2} \mathrm{q}_{\mathrm{e}}^{2} \mathrm{t}}{1+\mathrm{K}_{2} \mathrm{q}_{\mathrm{e}} \mathrm{t}}$ & $\frac{\mathrm{t}}{\mathrm{q}_{\mathrm{t}}}=\frac{1}{\mathrm{~K}_{2} \mathrm{q}_{\mathrm{e}}^{2}}+\frac{1}{\mathrm{q}_{\mathrm{e}}} \mathrm{t}$ & $\frac{\mathrm{t}}{\mathrm{q}_{\mathrm{t}}}$ vs. $\mathrm{t}$ & $(8)$ \\
\hline Intraparticle diffusion & $\mathrm{q}_{\mathrm{t}}=\mathrm{K}_{\mathrm{P}} \mathrm{t}^{1 / 2}+\mathrm{C}$ & & $\mathrm{q}_{\mathrm{t}}$ vs. $\mathrm{t}^{1 / 2}$ & $(9)$ \\
\hline Reichenberg model & $\mathrm{Q}=1-\frac{6 \mathrm{e}^{-\beta \mathrm{t}}}{\pi^{2}}$ & & $\beta \mathrm{t}$ vs. $\mathrm{t}$ & $(10)$ \\
\hline
\end{tabular}

\section{Pseudo second-order kinetic}

The nonlinear and the linear form of pseudo first-order kinetic is written as in Table 2 (Eq. (8)), where $\mathrm{K}_{2}$ is the pseudo second-order rate constant (g/mg-min). The value of rate constant $\mathrm{K}_{2}=$ slope $^{2}$ /intercept and $\mathrm{q}_{\mathrm{e}}=1 /$ slope $[22,36]$.

\section{Intraparticle diffusion model}

The most commonly used technique for identifying the mechanism involved in the adsorption process is by using intraparticle diffusion model as presented in Table 2 (Eq. (9)) [1], where $K_{p}$ is the intraparticle diffusion rate constant $\left(\mathrm{mg} / \mathrm{g} \cdot \mathrm{min}^{-1 / 2}\right)$ and $\mathrm{C}$ is the intercept $(\mathrm{mg} / \mathrm{g})[3,11]$. The value of $C$ provides evidence about the thickness of boundary layer, and for larger value of $C$, the boundary layer effect is greater $[14,35]$. In many adsorption cases, solute uptake varies almost proportionally with $\mathrm{t}^{1 / 2}$ rather than with the contact time $t[34,44]$. A plot of $q_{t} v s$. $t^{1 / 2}$ should be a straight line with a slope $K_{p}$ when the intraparticle diffusion is a rate-limiting step.

\section{Reichenberg model}

According to Reichenberg equation the radius of the adsorbent's particles (r) controls the effective diffusion of exchanging ions and film diffusion in adsorption may be reduced from the linear fit, as written in Table 2 (Eq. (10)) [25], where Q is the ratio of adsorbed concentration of the adsorbent $\left(q_{t}\right)$ at time' $t$ ' and the maximum adsorption capacity $\left(\mathrm{q}_{\mathrm{e}}\right)$ of the adsorbent, that is: 


$$
\begin{aligned}
& Q=\frac{\mathrm{q}_{t}}{\mathrm{q}_{\mathrm{e}}} \\
& \beta \mathrm{t}=\frac{\pi^{2} \mathrm{Di}}{\mathrm{r}^{2}}
\end{aligned}
$$

Where; Di is the coefficient of effective diffusion of ions exchanging inside the adsorbent particles. The value of $\beta$ t can be calculated

$$
\beta t=-0.4977-\ln (1-Q)
$$

The linear plot of ' $\beta \mathrm{t}$ ' versus contact time' $\mathrm{t}$ ' represents the Reichenberg kinetic equation model [15].

\section{Error functions}

The correlation coefficient $\left(\mathrm{R}^{2}\right)$ is based on the linear forms of the isotherm equations but does not represent the errors in the isotherm curves [38]. The evaluation of fitness of the model equations with experimental data requires an error functions with optimization [19]. The isotherms adsorption model fitness was signified by the coefficient of determination $\left(\mathrm{R}^{2}\right)$, nonlinear error functions: the residual root mean square error (RMSE) and the chi-square test $\left(\chi^{2}\right)$, the standard equations are as written in Table 3 (Eqs. (14, 15 and 16)) respectively [24], where $q_{e, x}$ is the mathematically for each value of $\mathrm{Q}$ using the following equation, Eq. (13):

equilibrium adsorption capacity found from the batch experiment, $\mathrm{q}_{\mathrm{e}, \mathrm{m}}$ is the prediction from the isotherm model for corresponding to $\mathrm{C}_{\mathrm{e}}$ and $\mathrm{n}$ is the number of observations made. The small values of RMSE and $\chi^{2}$ indicate the better model fitting and the similarity of model with the experimental data respectively [24]. The kinetics adsorption model was optimised by correlation coefficient $\left(\mathrm{R}^{2}\right)$ along with nonlinear error functions: the degree of fitness was analysed by the average relative error (ARE) and normalized standard deviation (NSD), the standard equations are as written in Table 3 (Eqs. (17 and 18)) respectively [24]. If data from a model are similar to the experimental data, the error value will be a small number, and if they differ, it will be a large number [37].

Table-3: Lists of error functions

\begin{tabular}{|l|c|c|}
\hline Error function & Expression & Equation \\
\hline Coefficient of determination & $\mathrm{R}^{2}=\frac{1-\sum_{\mathrm{i}-1}^{\mathrm{n}}\left(\mathrm{q}_{\mathrm{e}, \mathrm{x}}-\mathrm{q}_{\mathrm{e}, \mathrm{m}}\right)^{2}}{\sum_{\mathrm{i}-1}\left(\mathrm{q}_{\mathrm{e}, \mathrm{x}}-\overline{\mathrm{q}}_{\mathrm{e}, \mathrm{x}}\right)}$ & (14) \\
\hline Chi-square test & $\chi^{2}=\sum_{\mathrm{i}=1}^{\frac{\left(\mathrm{q}_{\mathrm{e}, \mathrm{x}}-\mathrm{q}_{\mathrm{e}, \mathrm{m}}\right)^{2}}{\mathrm{q}_{\mathrm{e}, \mathrm{x}}}}$ & (15) \\
\hline Root mean square error & $\mathrm{ARE}=\frac{100}{\frac{1}{\mathrm{n}-1} \sum_{\mathrm{i}=1}^{\mathrm{n}}\left|\frac{\left(\mathrm{q}_{\mathrm{e}, \mathrm{x}}-\mathrm{q}_{\mathrm{e}, \mathrm{m}}\right)}{\mathrm{q}_{\mathrm{e}, \mathrm{x}}}\right|}$ & (16) \\
\hline Average relative error & $\mathrm{NSD}=100 \times \sqrt{\frac{1}{\mathrm{n}-1} \sum_{\mathrm{i}-1}^{\mathrm{n}}\left[\frac{\mathrm{q}_{\mathrm{e}, \mathrm{x}}-\mathrm{q}_{\mathrm{e}, \mathrm{m}}}{\mathrm{q}_{\mathrm{e}, \mathrm{x}}}\right]^{2}}$ & \\
\hline $\begin{array}{l}\text { Normalized } \\
\text { deviation }\end{array}$ & standard & \\
\hline
\end{tabular}

\section{RESULTS AND DISCUSSION}

\section{Effect of stirring speed and contact time}

The effect of initial azo dye methyl orange concentration was studied by varying the stirring speed as 100, 200, 300, 400 and $500 \mathrm{rpm}$ at constant temperature of $298 \mathrm{~K}$ and result suggested that the percentage adsorption increases with the increase of stirring speed at equilibrium as shown in Fig. 2. The effect of contact time on the adsorption capacity (Fig. 3) shows that the enhanced adsorption of azo dye methyl orange with the increase in stirring time may be due to boundary layer resistance to mass transfer in bulk solution and an increase in the kinetic energy of hydrated ions by increasing the stirring time, the boundary layer resistance will be reduced and there will be an increase in the mobility of ions in the solution [40]. The results further show that equilibrium was reached within 90 minutes, thus the adsorption capacity was constant thereafter, this result is important because equilibrium time is one of the important considerations for economical wastewater treatment applications. The maximum amount of azo dye was adsorbed within the first 90 minutes and thereafter no significant change in adsorption rate was recorded. 


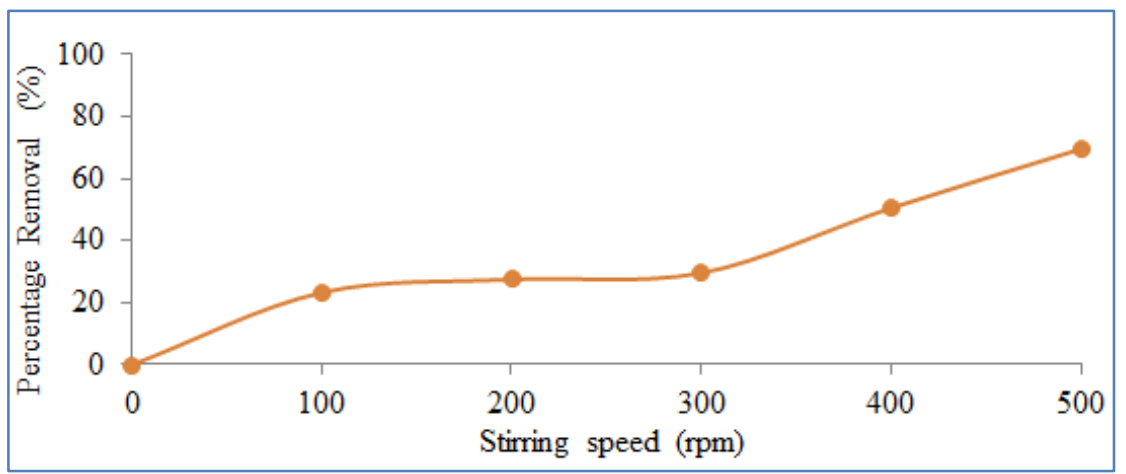

Fig-2: Removal of azo dye methyl orange at equilibrium as a function of stirring speed.

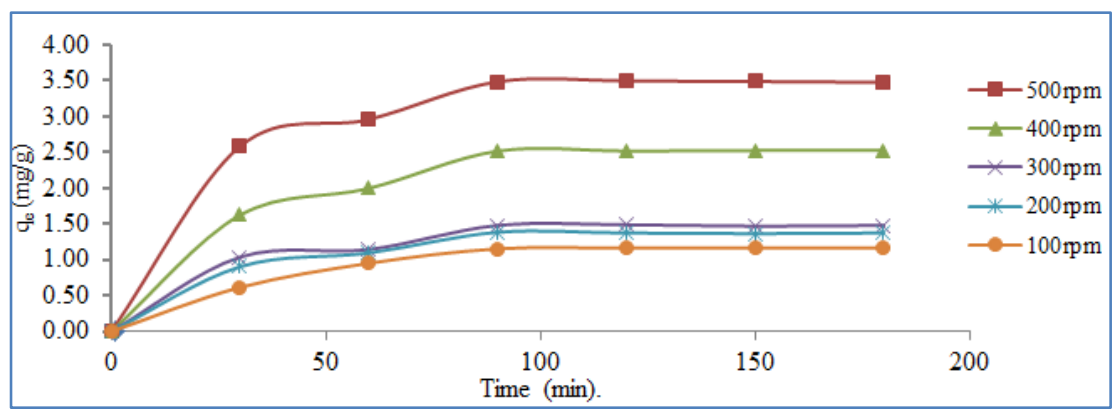

Fig-3: Adsorptive capacities of azo dye methyl orange onto kaolinite clay

In a liquid adsorption system, the mass transfer rate of solutes to a particle is affected by liquid film thickness surrounding the particle and the film thickness depends on stirring speed [4]. The results indicated that the degree of stirring influences the removal efficiency as the stirring rate increases from 100 to $500 \mathrm{rpm}$, the quantity of azo dye methyl orange adsorbed was low at lower stirring speed and practically high at higher speed hence it can be deduced that adsorption increases with stirring speed. The effect of contact time on the adsorption of azo dye methyl orange shows that the enhanced adsorption increases with stirring time may be due to boundary layer resistance to mass transfer in bulk solution an increase in the kinetic energy of hydrated ions by increasing the stirring time, the boundary layer resistance will be reduced and there will be an increase in the mobility of ions in the solution [40].

\section{Adsorption equilibrium}

To optimize the design of the adsorption processes, it is important to establish the most appropriate correlation for the equilibrium curves [32]. Three isotherms such as Langmuir, Freundlich and Koble-Corrigan had been used to evaluate the equilibrium characteristics of the adsorption processes. The parameters of the isotherm equations were calculated by linear regression analysis. The calculated adsorption parameter and correlation coefficient $\left(\mathrm{R}^{2}\right)$ for all the isotherms at 100, 200, 300, 400 and $500 \mathrm{rpm}$ are summarized in Table 1.

\section{Langmuir Isotherm}

A linear plot of $\mathrm{C}_{\mathrm{e}} / \mathrm{q}_{\mathrm{e}}$ versus $\mathrm{C}_{\mathrm{e}}$ was employed to determine the value of $\mathrm{q}_{\mathrm{o}}$ and $\mathrm{b}$, as shown in Fig. 4, and the parameters so obtained were presented in Table 1. The correlation coefficients $\left(\mathrm{R}^{2}\right)$ for Langmuir isotherm were in a range from $(0.9820-0.9970)$ for different stirring speed. The maximum adsorption capacity, $\mathrm{q}_{0}(\mathrm{mg} / \mathrm{g})$ was found to be $3.490 \mathrm{mg} / \mathrm{g}$ at 500 $\mathrm{rpm}$ with the corresponding correlation coefficient $\left(\mathrm{R}^{2}\right)$ 0.995 , so also experimental maximum adsorption capacity $\mathrm{q}_{\mathrm{e}}(\mathrm{mg} / \mathrm{g})$ was found to be $3.476(\mathrm{mg} / \mathrm{g})$ at the same stirring speed of $500 \mathrm{rpm}$. The values of $\mathrm{b}$ are negative showing that the energy of sorption may be exothermic [10]. Since the $\mathrm{R}_{\mathrm{L}}$ values evaluated were found to be out of range, it can be inferred that the adsorption of azo dye methyl orange contaminant onto kaolinite clay is undefined [10]. The applicability and favourability of the model was verified by the error analyses $\left(\chi^{2}\right.$ and RMSE) with error ranging between $(0.001-0.032)$ and $(0.012-0.058)$ for $\chi^{2}$ and RMSE respectively. The Langmuir isotherm showed a better fit to the adsorption of azo dye methyl orange onto kaolinite clay than the Freundlich and Koble-Corrigan isotherms since it gave a high correlation coefficient and further gave very low error functions of $\chi^{2}$ and RMSE [19]. 


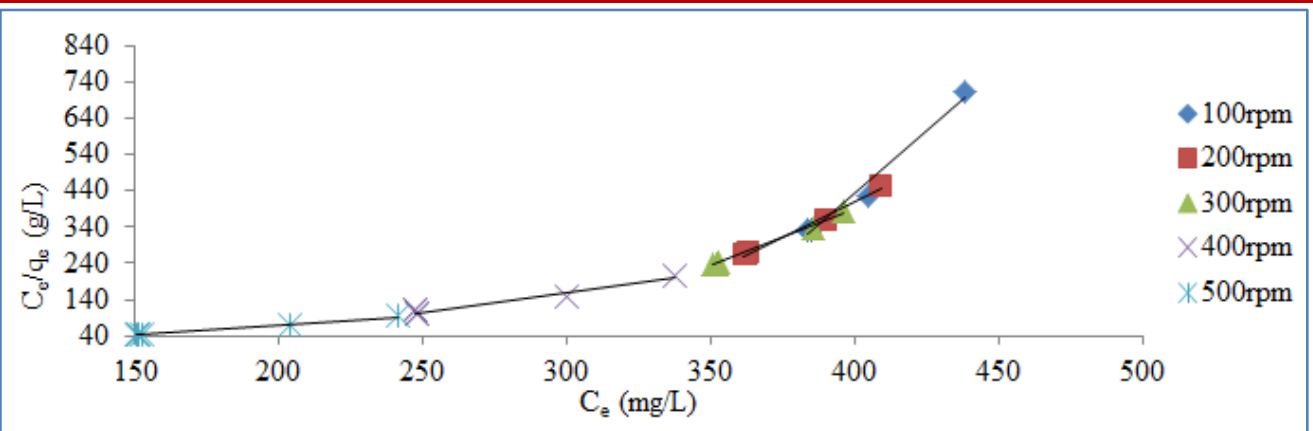

Fig-4: Langmiur isotherm for adsorption of azo dye methyl orange onto kaolinite clay

Table-1: Evaluated parameters for isotherms, kinetics and error analyses for adsorption of azo dye methyl orange dye onto kaolinite clay

\begin{tabular}{|c|c|c|c|c|c|c|}
\hline \multirow[b]{2}{*}{ Isotherm models } & \multirow[b]{2}{*}{ Parameters } & \multirow[b]{2}{*}{100} & \multicolumn{4}{|c|}{ Stirring speed (rpm) } \\
\hline & & & \multicolumn{2}{|c|}{$200 \quad 300$} & 400 & 500 \\
\hline Experiments & $\mathrm{q}_{\mathrm{e}}(\mathrm{mg} / \mathrm{g})_{\text {exp. }}$ & 1.162 & 1.374 & 1.479 & 2.256 & 3.476 \\
\hline \multirow[t]{6}{*}{ Langmuir } & $\mathrm{q}_{0}(\mathrm{mg} / \mathrm{g})_{\mathrm{cal}}$ & 1.191 & 1.381 & 1.481 & 2.41 & 3.490 \\
\hline & $\mathrm{b}(\mathrm{L} / \mathrm{mg})$ & -0.003 & -0.003 & -0.004 & -0.006 & -0.014 \\
\hline & $\mathrm{R}_{\mathrm{L}}$ & -2.062 & -1.440 & -1.239 & -0.446 & -0.167 \\
\hline & $\mathrm{R}^{2}$ & 0.982 & 0.991 & 0.997 & 0.968 & 0.996 \\
\hline & $\chi^{2}$ & 0.010 & 0.002 & 0.001 & 0.032 & 0.006 \\
\hline & RMSE & 0.043 & 0.022 & 0.012 & 0.123 & 0.058 \\
\hline \multirow[t]{5}{*}{ Freundlich } & $\mathrm{K}_{\mathrm{F}}(\mathrm{mg} / \mathrm{g})_{\text {cal. }}$ & $2.21 \mathrm{E}+12$ & $5.27 \mathrm{E}+08$ & $4.53 \mathrm{E}+07$ & $1.46 \mathrm{E}+03$ & $7.92 \mathrm{E}+01$ \\
\hline & $\mathrm{n}$ & -0.2105 & -0.2982 & -0.3402 & -0.8594 & -1.6085 \\
\hline & $\mathrm{R}^{2}$ & 0.993 & 0.997 & 0.999 & 0.887 & 0.994 \\
\hline & $\chi^{2}$ & 0.693 & 0.954 & 1.269 & 0.127 & 0.126 \\
\hline & RMSE & 0.400 & 0.511 & 0.589 & 0.244 & 0.291 \\
\hline \multirow[t]{6}{*}{ Koble- Corrigan } & $\mathrm{A}$ & 0.080 & 2.329 & 0.107 & 0.200 & 0.335 \\
\hline & $\mathrm{B}$ & 0.091 & 0.012 & 0.093 & 0.102 & 0.120 \\
\hline & $\mathrm{n}$ & 1.324 & 1.969 & 1.426 & 1.910 & 2.530 \\
\hline & $\mathrm{R}^{2}$ & 0.970 & 0.982 & 0.970 & 0.968 & 0.970 \\
\hline & $\chi^{2}$ & 0.394 & 0.974 & 0.320 & 0.568 & 0.594 \\
\hline & RMSE & 0.482 & 0.609 & 0.596 & 1.021 & 1.399 \\
\hline \multicolumn{7}{|l|}{ Kinetic models } \\
\hline \multirow[t]{5}{*}{ Pseudo first-order } & $\mathrm{q}_{\mathrm{e}}(\mathrm{mg} / \mathrm{g})_{\mathrm{cal}}$ & 10.46 & 1.371 & 1.458 & 16.77 & 3.654 \\
\hline & $\mathrm{K}_{1}\left(\mathrm{~min}^{-1}\right)$ & 0.081 & 0.038 & 0.038 & 0.074 & 0.006 \\
\hline & $\mathrm{R}^{2}$ & 0.952 & 0.863 & 0.856 & 0.910 & 0.884 \\
\hline & ARE & -130.6 & 6.535 & 8.490 & -68.62 & 40.83 \\
\hline & NSD & 385.5 & 0.468 & 1.124 & 401.027 & 3.805 \\
\hline \multirow[t]{5}{*}{ Pseudo second-order } & $\mathrm{q}_{\mathrm{e}}(\mathrm{mg} / \mathrm{g})_{\mathrm{cal}}$ & 1.388 & 1.551 & 1.660 & 2.894 & 3.782 \\
\hline & $\mathrm{K}_{2}(\mathrm{~g} / \mathrm{mg} \min )$ & 0.025 & 0.033 & 0.032 & 0.016 & 0.021 \\
\hline & $\mathrm{R}^{2}$ & 0.984 & 0.991 & 0.990 & 0.992 & 0.996 \\
\hline & ARE & -0.521 & 4.366 & 6.227 & 2.299 & 4.022 \\
\hline & NSD & 9.339 & 6.376 & 6.286 & 10.353 & 6.864 \\
\hline \multirow[t]{6}{*}{ Intraparticle diffusion } & $\mathrm{K}_{\mathrm{p}}\left(\mathrm{g} / \mathrm{mg} \cdot \min ^{0.5}\right)$ & 0.066 & 0.061 & 0.062 & 0.081 & 0.117 \\
\hline & $\mathrm{q}_{\mathrm{e}}(\mathrm{mg} / \mathrm{g})_{\mathrm{cal}}$ & 1.265 & 1.465 & 1.569 & 2.480 & 3.662 \\
\hline & $\mathrm{C}$ & 0.383 & 0.645 & 0.741 & 1.391 & 2.088 \\
\hline & $\mathrm{R}^{2}$ & 0.768 & 0.786 & 0.788 & 0.493 & 0.792 \\
\hline & ARE & -0.448 & -0.596 & -0.448 & -1.071 & -0.276 \\
\hline & NSD & 6.752 & 7.413 & 6.752 & 10.872 & 5.375 \\
\hline \multirow[t]{5}{*}{ Reichenberg equation } & $\mathrm{q}_{\mathrm{e}}(\mathrm{mg} / \mathrm{g})_{\mathrm{cal}}$ & 0.529 & 0.657 & 0.702 & 0.643 & 0.743 \\
\hline & $\mathrm{B}_{\mathrm{t}}$ & 4.299 & 4.466 & 4.540 & 5.075 & 1.425 \\
\hline & $\mathrm{R}^{2}$ & 0.713 & 0.756 & 0.723 & 0.703 & 0.454 \\
\hline & ARE & 17.251 & 27.199 & 32.39 & 60.41 & 71.23 \\
\hline & NSD & 29.052 & 29.795 & 35.48 & 66.17 & 78.03 \\
\hline
\end{tabular}




\section{Freundlich isotherm}

The Freundlich isotherm constants were evaluated from the linear plot of $\log \mathrm{q}_{\mathrm{e}}$ versus $\log \mathrm{C}_{\mathrm{e}}$ as shown in Fig. 5 and parameters presented as in Table 1. The adsorption intensity (n) varied from (-0.211 - 1.619) for adsorption of azo dye methyl orange. The values of the adsorption intensities obtained are not in conformity with the requirement for physical adsorption process, which characterize it to be unfavourable [23], hence favourability of the process is achieved if $\mathrm{n}$ lies in the range of $(1-10)$. Since the values of $(n$ and $1 / n)$ were negative which are below unity implies chemisorption [42]. $\mathrm{K}_{\mathrm{F}}$ are very high and decreases with increase in stirring speed, which implies that the adsorption of azo dye methyl orange contaminant onto kaolinite clay is very fast. The correlation coefficients ranging between $(0.887-0.999)$, although the Freundlich isotherm did not show a good fit to the experimental data as indicated by $\chi^{2}(0.126-1.269)$ and RMSE (0.244 - 0.589) compared to Langmuir isotherm.

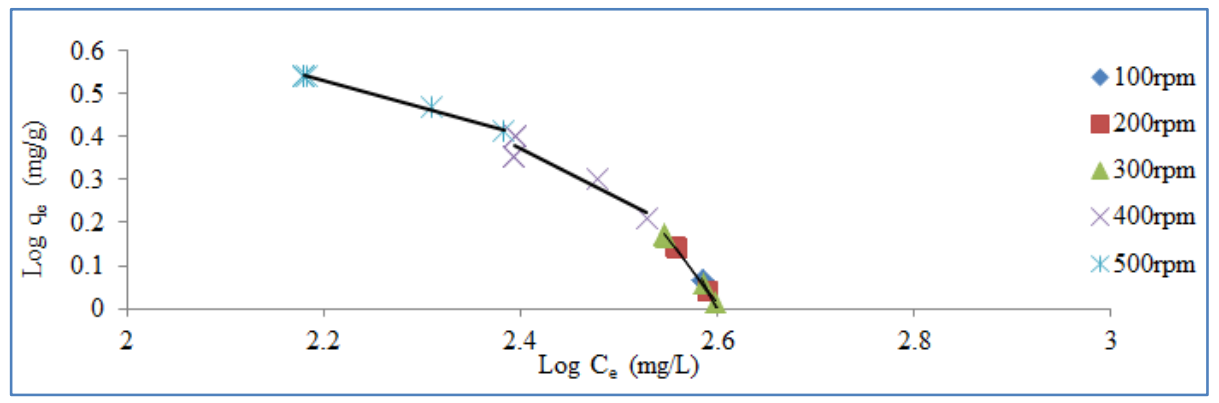

Fig-5: Freundlich isotherm for adsorption of azo dye methyl orange onto kaolinite clay

\section{Koble-Corrigan isotherm}

A plot of $1 /$ qe versus $1 / C_{e}{ }^{n}$ enables the determination of isotherm constants, as shown in Fig. 6 and the isotherm parameters are listed in Table 1. The values of $\mathrm{n}$ ranges between $(1.324-2.530)$ which shows the validity of this model: thus, the model is valid only when $n>1$ [30]. The constants $\mathrm{A}$, B were less than unity showing that the surface of the adsorbent for the adsorption may be heterogeneous with a different energy distribution [30]. Therefore, these revealed that the processes were controlled by chemisorption [24]. The correlation coefficients ranging between $(0.932-0.996)$ with lower $\chi^{2}$ and RMSE values ranging between $(0.394-0.594)$ and $(0.482-$ 1.399) respectively. The isotherm did not show a good fit despite lower error functions when compared to Langmuir and Freundlich isotherm models.

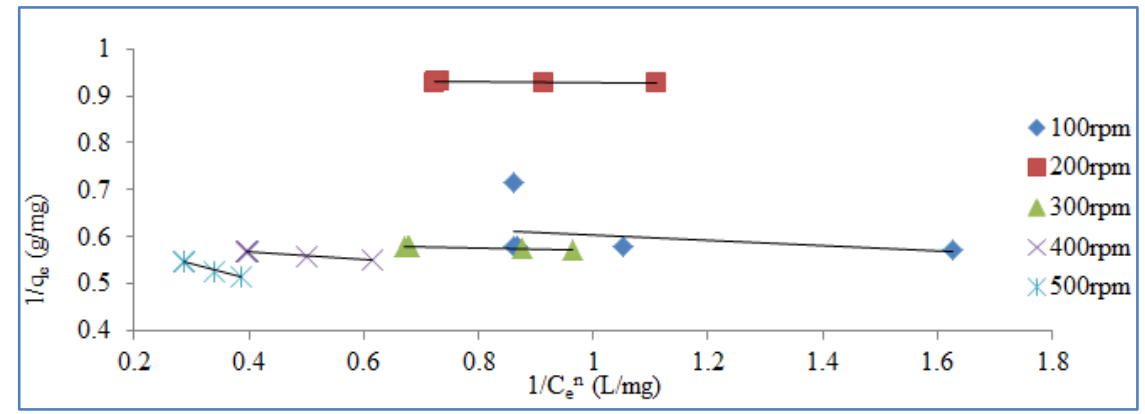

Fig-6: Koble-Corrigan isotherm for adsorption of azo dye methyl orange onto kaolinite clay

\section{Adsorption kinetics}

Adsorption kinetics provides valuable information about the controlling mechanism of the adsorption process rate of the adsorbate uptake and optimum operating conditions for the full-scale batch process [39]. The kinetic data for the adsorption of azo dye methyl orange onto kaolinite clay were tested with well-known kinetic models namely pseudo first-order and pseudo second-order model. The mechanism of the adsorption processes was studied by plotting the data with intraparticle diffusion and Reichenberg plot. The parameters of these kinetic models are given in Table 1.

\section{Pseudo first-order kinetics}

The linear plot of model for evaluation of $\mathrm{K}_{1}$ $\left(\mathrm{min}^{-1}\right)$ and $\mathrm{q}_{\mathrm{e}}(\mathrm{mg} / \mathrm{g})$ is shown in Fig. 7 and parameters presented in Table 1. The model predicted $\mathrm{q}_{\mathrm{e}}$ maximum values at 100 and $400 \mathrm{rpm}$ that could not be reached in the experiments which signifies that the reaction is fast at these stirring speeds but showed irregularities with very large NSD and ARE. The rate constant $\mathrm{K}_{1}$ ranging between $(0.006-0.081) \mathrm{min}^{-1}$ with correlation coefficient $\left(R^{2}\right)$ ranging between $(0.884-0.952)$, thus the sorption of azo dye methyl orange onto kaolinite clay does not fit the Pseudo first-order kinetic model. 


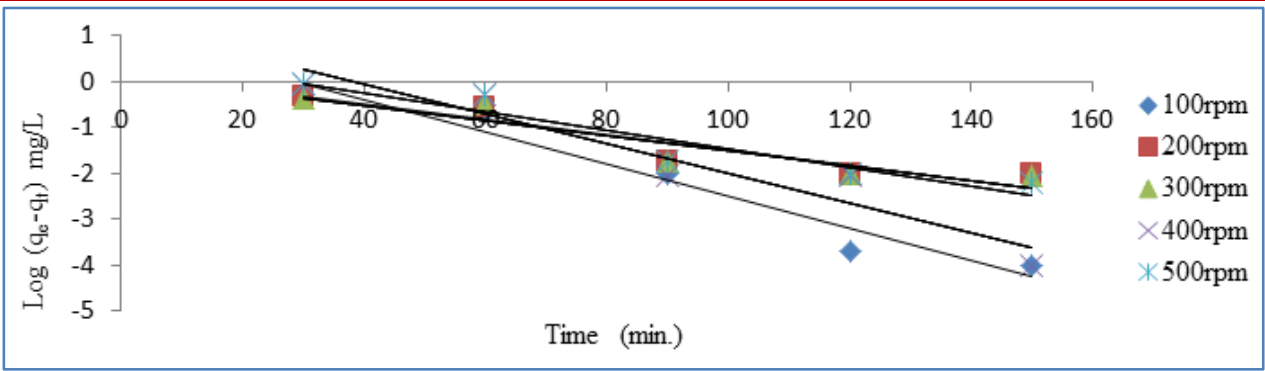

Fig. 7: Pseudo-first order kinetic model for adsorption of azo dye methyl orange onto kaolinite clay

\section{Pseudo second-order kinetics}

The linear plot of $\mathrm{q}_{\mathrm{e}} / \mathrm{q}_{\mathrm{t}}$ versus $\mathrm{t}$ enables determinations of constants from the slope and intercept as shown in Fig. 8 and evaluated parameters presented in Table 1 . The rate constant $\mathrm{K}_{2}$ ranging between (0.016 $-0.033) \mathrm{g} / \mathrm{mg}$. min and $\mathrm{q}_{\mathrm{e}}$ increases with increase in stirring speed with high correlation coefficient $\left(\mathrm{R}^{2}\right)$ ranging between $(0.984-0.996)$ compared with other models tested. The maximum adsorption capacity $\left(\mathrm{q}_{\mathrm{e}}\right)$ calculated showed slight variation which culminated into smaller values of error functions NSD and ARE ranging between $(6.286-10.353)$ and $(-0.521-4.022)$ respectively. The results revealed that pseudo secondorder kinetic model is the most appropriate that describe the sorption of azo dye methyl orange onto kaolinite.

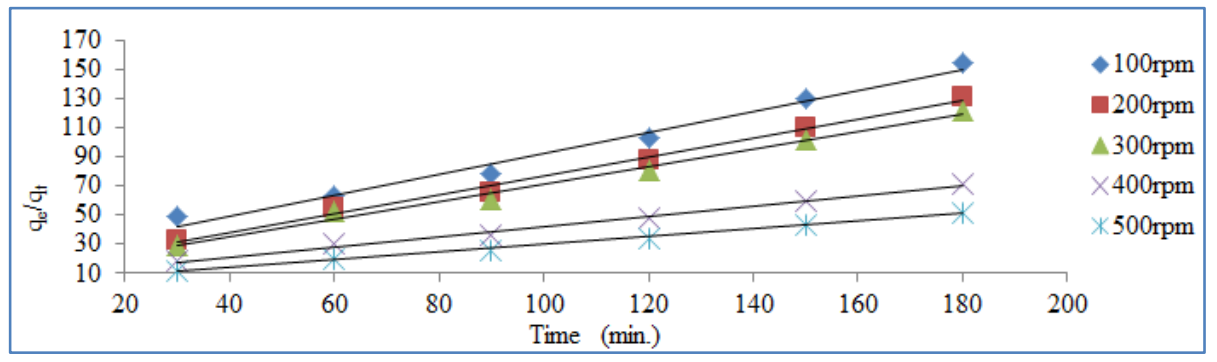

Fig-8: Pseudo-second order kinetic model for adsorption of azo dye methyl orange onto kaolinite clay

\section{Intraparticle diffusion model}

The plot of intraparticle diffusion is shown in Fig. 9 and the evaluated parameters presented in Table 1. The plots for varying stirring speed showed a poor fit with low correlation coefficient $\left(\mathrm{R}^{2}\right)$ values ranging between $(0.493-0.792)$, despite relatively small values of ARE and NSD (Table 1). The $\mathrm{q}_{\mathrm{t}} \mathrm{vs} . \mathrm{t}^{1 / 2}$ plots does not pass through the origin which indicates that there is boundary layer resistance which suggested that the intraparticle diffusion was not the only step controlling adsorption of the azo dye methyl orange [46].

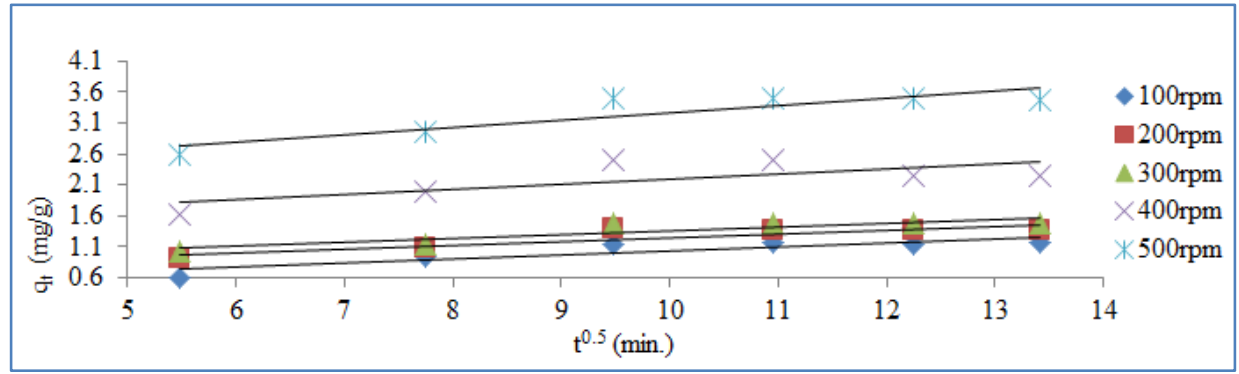

Fig-9: Intraparticle diffusion model for adsorption of azo dye methyl orange onto kaolinite clay

\section{Reichenberg equation}

The linear plot of ' $\beta \mathrm{t}$ ' versus contact time ' $\mathrm{t}$ ' as shown in Fig. 10 and evaluated parameters presented in Table 1 . The data were quite unfit for the Reichenberg model equation as it gives low correlation coefficient $\left(\mathrm{R}^{2}\right)$ values ranging between $(0.454-0.756)$, thus the significantly high values of NSD and ARE ranging $(29.052-78.030)$ and $(17.211-71.231)$ respectively. 


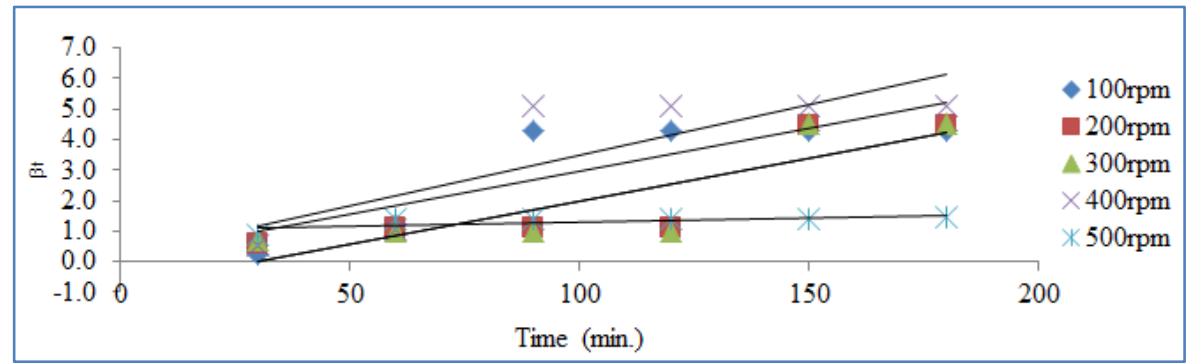

Fig-10: Rechienberg model for adsorption of azo dye methyl orange onto kaolinite clay

\section{CONCLUSIONS}

The study revealed that adsorption process of azo dye methyl orange onto kaolinite clay is feasible and removal of azo dye methyl orange increases with increase in stirring speed applied in this work with maximum adsorption capacity of $3.476 \mathrm{mg} / \mathrm{g}$ at 500 $\mathrm{rpm}$ and maximum percentage removal of $69.90 \%$ at 120 minutes. The experimental data relatively fitted well with Langmuir and Freundlich models based on correlation coefficients but relatively small error functions ( $\chi^{2}$ and RMSE) of Langmuir compared with Freundlich and Koble-Corrigan shows preference for Langmuir model. The kinetics of azo dye methyl orange adsorption onto kaolinite clay fits pseudo second-order model based on correlation coefficients and relatively small error deviation as compared with the pseudo firstorder model, intraparticle diffusion and Reichenberg model. These results indicated that kaolinite clay could be employed as a low-cost adsorbent alternative to commercial activated carbon in the removal of azo dye methyl orange from wastewater.

\section{REFERENCES}

1. Abdelwahab, O. (2007). Kinetic and Isotherm Studies of Copper (II) Removal from Wastewater Using Various Adsorbents, Egyptian Journal of Aquatic Research, 33(1)125-143.

2. Adeniran, K. A., Ahaneku I. E., Itodo I. N., \& Rohjy H. A. (2014). Relative Effectiveness of Biogas Production Using Poultry Wastes and Cow Dung. Agric. Eng. Int: CIGR Journal, 16(1)126132.

3. Aksu, Z. (2005). Application of Biosorption for The Removal of Organic Pollutants: A review. Process Biochemistry; 997-1002.

4. Albroomi, H., Elsayed, M., Baraka, A., \& Abdelmaged, M. (2015). Factors Affecting the Removal of a Basic and an Azo Dye from Artificial Solutions Using Activated Carbon. Journal of the Turkish Chemical Society, Section A: Chemistry; 2(1)17-33.

5. Allen S. J., McKay, G., \& Porter, J. F. (2004). Adsorption Isotherm Models for Basic Dye Adsorption by Peat in Single and Binary Component Systems. J. Colloid Interf. Sci., 280(2)322-333.

6. Anguile, J. J., Mbadcam, J. K., Ndaghu, D.D., \& Dongmo, S. (2013). Effect of Solution Parameters on the Adsorption of Cobalt (II) Ions on Smectite from Cameroon: Equilibrium Studies, Journal of Academia and Industrial Research, 2(4)210-215.

7. Aroke, U. O., \& El-Nafaty U. A. (2014). XRF, XRD and FTIR Properties and Characterization of HDTMA-Br Surface Modified Organo-Kaolinite Clay, International Journal of Emerging Technology and Advanced Engineering, 4(4)817825.

8. Aroke, U. O., El-Nafaty U. A., \& Osha O. A. (2016). Characterization, Synthesis and Application of Organo-Kaolinite Clay, Lambert Academy Publishing, Germany.

9. Aroke, U. O., El-Nafaty, U.A., \& Osha, O. A. (2013). Properties and Characterization of Kaolin Clay from Alkaleri, North-Eastern Nigeria, International Journal of Emerging Technology and Advanced Engineering, 3(11)387-392.

10. Aroke, U. O., Ibrahim, M., \& Okoroma I. A. (2015). Parametric Studies of Nitrate Ion Sorption on varied Mass of HDTMA-Br Modified Kaolinite Clay. International Journal of Emerging Technology and Advanced Engineering, 5(3)14-23.

11. Bulut, Y., Gozubenli, N., \& Aydm H. (2007). Equilibrium and Kinetics Studies of Adsorption of Direct Blue 71 from Aqueous Solution by Wheat Shells. J. Hazard. Mater. 144:303-305.

12. Crini, G. (2006). Non- conventional Low- Cost Adsorbent for Dye Removal. A review: Bioresource Technology, 97:1061-1085.

13. Dawood, S., \& Sen, T. (2014). Review on Dye Removal from Its Aqueous Solution into Alternative Cost Effective and Non-Conventional Adsorbents. Journal of Chemical and Process Engineering. 1:1-11.

14. Dogan, M., \& Alkan, M. (2003). Adsorption Kinetics of Methylene Violet onto Perilite. Chemo. 50:522-523.

15. Elhadad, E. \& Tantawy S. T. (2015). Equilibrium Kinetic Studies of Biosorption of $\mathrm{Cr}$ (III) and $\mathrm{Cd}$ (II) by Activated Carbon Prepared from Spirulina Algae. Journal of Biodiversity and Environmental Sciences (JBES), 7(3)132-140.

16. Foo, K. Y., \& Hameed, B. H. (2010). Insights into the Modeling of Adsorption Isotherm Systems, Chemical Engineering Journal, 156:2-10.

17. Fortunate, P. S., \& Misael, S. N. (2016). Removal of Methyl Orange (MO) from Water by Adsorption onto Modified Local Clay (Kaolinite). Physical Chemistry, 6(2):39-48. 
18. Guivarch, E., Trevin, S., \& Lahitte, C. (2003). Degradation of Azo dyes in Water by ElectroFenton Process. Env. Chem. Lett. 1:30-42.

19. Han, R., Zhang, J., Han P., Wang Y., Zhao, Z., \& Tang M. (2009). Study of Equilibrium, Kinetic and Thermodynamic Parameters about Methylene Blue Adsorption onto Natural Zeolite. Chemical Engineering. 496-504, journal homepage: www.elsevier.com/locate/cej.

20. Hamidu, L. A. J., Aroke U. O., \& Ahmed, S. I. (2017). Desulphurization of Liquid Fuel Kerosene onto Unmodified and HDTMA-Br Modified Kaolinite Clay: Equilibrium, Isotherm and Kinetic Studies, International Journal of Advanced Research in Management Engineering Technology, 2(6), $836-846$.

21. Ho, Y. S. (2006). Review of Second-Order Models for Adsorption Systems, Journal of Hazardous Materials, B136: 681-689.

22. Ho Y. S. \& Mckay G. (1999). Pseudo-second Order Model for Sorption Process, Process Biochem, 34(5)451-465.

23. Ho, Y. S., Porter J. F., \& Mckay, G. (2001). Equilibrium Isotherm Studies for the Sorption of Divalent Metal Ions into Peat: Copper Nickel And Lead Single Component Systems, Water Air Soil Pollution, 1(2)141-174.

24. Hossain, M. A., Ngo, H. H., Guo, W. S., \& Nguyen, T.V. (2012). Biosorption of $\mathrm{Cu}$ (II) from Water by Banana Peel Based Biosorbent: Experiments and Models of Adsorption and Desorption, Journal of Water Sustainability, 2(1)87-104.

25. Hossain, M. A., Ngo, H. H., Guo, W. S., \& Nguyen, T.V. (2012). Removal of Copper from Water by Adsorption onto Banana Peel as Bioadsorbent, Int. J. of GEOMATE, 2(2)227-234.

26. Hung-Yee, S., \& Ming-Chin, C. (2005). Decolorization Effects of Six Azo Dyes by $\mathrm{O}_{3}$, $\mathrm{UV} / \mathrm{O}_{3}$ and $\mathrm{UV} / \mathrm{H}_{2} \mathrm{O}_{2}$ Processes. Dyes Pigments, 65:25-31.

27. Jock, A. A., Abdulsalam, S., El-Nafaty U. A., Aroke U. O., \& Muhammad, A. A. Z. (2017). Multimetals Column Adsorption of Lead (II), Cadmium (II) And Manganese (II) Onto Natural Bentonite Clay, Water Science and Technology, doi:10.2166/wst.2017.391 pp.2232-2241.

28. Khan, M. A., \& Ho, Y. S. (2015). Impact of Brunauer Emmett Teller Isotherm on Research in Science Citation Index Expanded, Environmental Engineering and Management Journal, 14(9)21632168.

29. Kumar K. V. (2006). Linear and Non-Linear Regression Analysis for the Sorption Kinetics of Methylene Blue onto Activated Carbon, Journal of Hazardous Materials B137: 1538-1544

30. Muhammad M. S. \& Ali B. (2011). Modelling of Equilibrium Data for Free Cyanide Adsorption onto Activated Carbon By Linear and Non-Linear Regression Methods. International Conference on
Environment and Industrial Innovation. IPCBEE IACSIT Press, Singapore 12:79-84.

31. Musleh, S. M. (2014). Properties and Characterization of HDTMA-Cl Modified Jordanian kaolinite and its use in Removal of Aniline from Aqueous Solution, International Journal of Scientific Research, 3(10)74-78.

32. Nethaji, S., Sivasamy, A., \& Mandal, A. B. (2011). Adsorption Isotherms, Kinetics And Mechanism for the Adsorption of Cationic and Anionic Dyes onto Carbonaceous Particles Prepared from Juglans Regia Shell Biomass, Int. J. Environ. Sci. Technol. 10:231-242

33. O'Neill, C., Lopez, A., Esteves, S., Hawkes, F. R., Hawkes, D. L., \& Wilcox, S. (2000). Azo-dye Degradation in an Anaerobic and Aerobic Treatment System Operating On Simulated Textile Effluent. -Appl. Microbiol. Biotechnol, 53-67.

34. Qiu, H., Pan, B. C., Zhang, Q. J., Zhang, W. M., \& Zhang Q. X. (2009). Critical Review in Adsorption Kinetic Models, Journal of Zhejiang University Science, 10(5)716-724.

35. Rajoriya, R. K., Prasad, B., Mishra, I. M., \& Wasewar, K. L. (2007). Adsorption of Benzaldehyde on Granular Activated Carbon: Kinetics, Equilibrium and Thermodynamics. Chem. Biochem.Eng. Q. 21:221-224.

36. Robati, D. (2013). Pseud-second-order Kinetic Equations for Modelling Adsorption Systems for Removal of Lead Ions Using Multi-Walled Carbon Nanotube, Journal of Nanostructure in Chemistry 3:55.

37. Saadi, R., Saadi, Z., Fazaeli, R., \& Fard N. E. (2015). Monolayer and Multilayer Adsorption Isotherm Models for Sorption from Aqueous Media, Korean J. Chem. Eng., 32(5)787-799.

38. Sampranpiboon, P., Charnkeitkong, P., \& Feng, X. (2014). Equilibrium Isotherm Models for Adsorption of Zinc (II) Ion from Aqueous Solution on Pulp Waste, WSEAS TRANSACTIONS on EVIRONMENT and DEVELOPMENT, volume 10.

39. Saravanan, R., \& Ravikumar, L. (2015). The use of new Chemically Modified Cellulose for Heavy Metal Ion Adsorption and Antimicrobial Activities, Journal of Water Resource and Protection, (7)530545.

40. Saritha, B., Rajasekhar, K., \& Khriezo, K. (2015). Equilibrium Studies of Methylene Blue from Aqueous Solution Using Low-Cost Adsorbent, International Journal of Innovative Research in Science, Engineering and Technology, 4: 68216827.

41. Shah, K. (2014). Biodegradation of Azo Dye compounds. International Research Journal of Biochemistry and Biotechnology, 1(2):005-013.

42. Shahbeig, H., Bagheri, N., Ghorbanian, S. A., Hallajisani, A., \& Poorkarimi, S. (2013). A new Adsorption Isotherm Model of Aqueous Solutions 
on Granular Activated Carbon, World Journal of Modelling and Simulation, 9(4)243-254.

43. Sudha, M., Saranya, A., Selvakumar, G., \& Sivakumar, N. (2014). Microbial Degradation of Azo Dyes: A review: Int. J. Curr. Microbiol. App. Sci, 3(2)670-690.

44. Wang, S., \& Wu, H. (2006). Environmental Benign Utilization of Fly Ash as Low-Cost Adsorbent. J. Hazard. Mater. B136:490-500.

45. Waranusantigul, P., Pokethitiyook, P., Kruatrachue, M., \& Upatham, E. S. (2003). Kinetics of Basic Dye (Methylene Blue) Biosorption by Giant Duckweed (Spiraodela polyrrhiza). Env. Pol. 125:385-391.

46. Wu, C.H. (2007). Adsorption of Reactive Dyes onto Carbon Nanotubes: Equilibrium, Kinetics and Thermodynamics. J. Hazard. Mater. 144:96-98.
47. Zaharia, C., \& Suteu, D. (2012). Textile Organic Dye-Characteristics, Polluting Effects and Separation/Elimination Procedures from Industrial Effluents. A Critical Overview, Organic Pollutants Ten Years after the Stockholm Convention, Environmental and Analytical Update, 55-86.

48. Zollinger, H. (1987). Azo Dyes and Pigments. Colour Chemistry-Synthesis, Properties and Applications of Organic Dyes and Pigments. Color Chemistry. New York, USA: VCH Publishers; 92102.

49. Zollinger, H. (1991). Synthesis, Properties and Application of Organic Dyes and Pigments, Colour Chemistry: New York, USA: VCH Publishers: 496: 456-980. 